\title{
Palestinians Born in Exile: Diaspora and the Search for a Homeland
}

\author{
Juliane Hammer
}

Austin: University of Texas Press, 2005. 271 pages.

There is a striking lack of studies on the Palestinian diaspora. Undoubtedly the pioneering work of Edward Said ("Reflections on Exile," in Out There: Marginalization and Contemporary Cultures, eds. Russell Ferguson [The MIT Press: 1990]) on exile and Rashid Khalidi (Palestinian Identity: The Construction of Modern National Consciousness [Columbia University Press: 1997]) both touch on many of the related issues of collective memory, cultural identity, and the relationship between the "center" (the homeland) and the diasporic communities and how these issues manifested themselves in the Palestinian case. More recently, Abbas Shiblak (Reflections on Palestinian Diaspora in Europe [2000]), Sari Hanafi (Here and There: Analyses of the Relationship between Diaspora and the Centre [2001: in Arabic]), and Helena Schulz and Juliane Hammer (The Palestinian Diaspora: Formation of Identities and Politics of Homeland [Routledge: 2003]) explore different aspects of the Palestinian diaspora.

Juliane Hammer's new study examines young Palestinian returnees as part of a larger social, historical, political, and cultural framework (p. 114). She conducted her research in the mid-1990s, a crucial period between two phases: one of peace and hope following the signing of the Declaration of Principles in 1993, and another one that started in 1997 with the deterioration and breakdown of the peace talks, and, consequently, with the eruption of the second Intifada in 2000. For her survey, she chose a sample of two main categories of young returnees: those of the Palestinian Authority strata (a idin) and the children of Palestinian expatriates who live in the West but mainly in the United States (Amerikans). The interviewees were mainly adolescent or young men and women from and around Ramalla and Jerusalem.

The return process has been described chronologically, as a series of five steps or stages ranging from the decision to return to plans for the near future. As the study argues, this return entails a process of the returnees' rewriting aspects of their identities. Hammer does not see, however, that the chronological approach is the only way of looking at the process of return. She sees the transformation (what she calls the "rewriting of identities") also by dividing "identity" into different aspects, and then investigating how the respondents remembered these aspects from their childhood and youth in the 
diaspora and which changes might have occurred during the process of return (p. 166).

To put it differently, Hammer sees that the return process took place inside the returnees, taking the form of a "challenge" to the identity they had formed in exile. This return process has been described in pre-liminal and post-liminal stages. She sees the concept of liminality as enabling us to recognize the return as occurring in different stages, yet "it stresses the fluidity of the process" (p. 117). Indeed, Palestinian identities have developed differently in various host countries. This led Hammer to build on a concept of changing identities and to argue for recognizing the multiple nature of personal, political, and cultural identities within every individual (p. 220). The study's empirical material clearly demonstrates this, and the young respondents substantiate this claim.

The author points out that the young returnees temporarily lost their social identities and had "to negotiate their position in the newly founded Palestinian society" (p. 222): "They were forced to recognize the realities of Palestine, to compare them to their images, and to cope with the discrepancies” (p. 222). They had to adjust their concept of identity while attempting, at the same time, to change the realities of Palestinian society. The study shows that the respondents exercised both options, "in many cases combining the two through a long and painful process of negotiation” (p. 222). Some recognized the new realities and had to live with them, integrate, and accept Palestine as their real "home." Others had to cope with what Hammer calls "eternal liminality," defined as being torn among other factors: love of their country, strong family ties, shrinking space, diminishing job opportunities and their longing to be free, some stability, better education, and settling down and starting a family.

This state of being transnational with a floating idea of "home" and nationality is better explained by Hammer in her concluding remarks, where she states that it could be "as much a blessing as a burden" (p. 222). Where it was perceived as a burden, the young returnees tended to have future plans to settle down, build a career, and start a family "to ensure that they might feel at home somewhere someday” (p. 222). Those who saw their transnationalism as a blessing "stressed the choice and opportunities that were also a characteristic of their youth" (p. 222).

Hammer recognizes that it will be difficult to look at the Palestinian diaspora as merely a case of migrancy and globalization (p. 220). Unlike other diasporic communities, the Palestinians are denied the option of return to the homeland or even to the Palestinian Authority-controlled area. The 
"center" is simply not there for the majority of them. Palestine is what they know through their parents or grandparents and what they read or see on the small screen. While the option of a real return or even a visit is denied, the gap between what is "real" and "virtual" will increase.

The two categories of young respondents are the fortunate few who, more than the rest, would be able to narrow the gap. Hammer left them to reflect on their search of "home” and experience of "return.” Through apparently informal chats with her respondents, She has produced a solid academic work that offers insights into the very complicated and multi-layered issues of how young Palestinians perceive home and going through the agonizing process of adjustment and readjustment with the realties of coming home and with the fluid nature and diverse identities of Palestinian diasporic communities.

Abbas Shiblak 